\title{
Plain cigarette packaging: A policy analysis of Australia's integrated "whole-of-system" model for smoking cessation
}

\author{
Lorraine Davies, Erica Bell* \\ University Department of Rural Health, University of Tasmania, Hobart, Australia; \\ *Corresponding Author: erica.bell@utas.edu.au
}

Received 22 October 2012; revised 25 November 2012; accepted 30 November 2012

\section{ABSTRACT}

Introduction: Plain cigarette packaging as a tobacco control measure is to be implemented in Australia on December 1st 2012. There is mounting evidence for its likely impact on smokers and potential smokers. Yet Australia's integrated model of smoking cessation and the particular role and opportunities it has created for primary healthcare have not yet been subject to policy analysis in leading international journals. This policy analysis paper explores these new Australian policy developments and debates in ways that identify their international relevance to primary healthcare. Policy analysis: There are 57 studies about plain cigarette packaging published since 2002 . Of these, 27 looked at the impact of health warnings. These studies support the introduction of plain packaging as a tobacco control measure, by increasing the efficacy of health warnings and reducing misconceptions about cigarettes. However, the Australian tobacco control reforms are not limited to plain cigarette packaging. They include other evidence-based tobacco control measures as part of its primary health care strategy: for example, increasing tobacco excises, a mass media campaign focusing on high-risk and hard-to-reach groups, and a national summit on smoking in prisons. The Australian government has acknowledged the key role of primary health care in health promotion activities, establishing a network of regional primary health care organisations ("medicare locals") in 2011-2012, and expanding the role of nurses in general practice. These initiatives offer general practice a chance to seize "golden opportunities to intervene with smoking patients". Conclusions: Whether the combined impact of the Australian government's recent tobacco control reforms and its previous measures will be sufficient to reduce daily smoking prevalence to $10 \%$ or less by 2020 , only time will tell. What is more certain is that the Australian experience of plain packaging offers international colleagues in general practice key lessons about the importance of "whole-of-system" approaches, integrating efforts at the local to national levels, to tackle smoking cessation. The achievement of Australia's political leaders in plain cigarette packaging is an extraordinary testament to political will but there is no room for complacency. Primary healthcare sectors must continue to lobby political leaders around the world to tackle smoking at the system level where the motivations and beliefs about smoking are being shaped, especially among disadvantaged groups with lower health literacy.

Keywords: Tobacco Control Measures; Primary Healthcare Smoking Interventions; Smoking Cessation

\section{INTRODUCTION}

Plain cigarette packaging was first proposed in Canada and New Zealand in the late 1980s [1]. In 1994 the Canadian government commissioned an expert panel to examine plain packaging as part of its Tobacco Demand Reduction Strategy. The ensuing report [2] on the panel's comprehensive and multi-layered study concluded that plain packaging would both deter the uptake of smoking and increase the likelihood of smokers quitting. However, debate over whether the mandating of plain packaging would infringe international trade obligations and intellectual property rights stymied further action in Canada, as in other countries.

In 2005, the WHO Framework Convention on Tobacco Control (FCTC) came into force, specifying a range of 
evidence-based measures to reduce the supply of, and demand for, tobacco products in nations signatory to the Convention. In October 2008, the FCTC strengthened its guidelines for cigarette package labelling (Article 11), recommending the use of plain packaging [1].

In November 2011, the Australian Parliament passed two amended Tobacco Plain Packaging bills [3], which will require tobacco companies to adopt standardised brown packaging for cigarettes, with large graphic health warnings and minimal brand identification, by 1 December 2012. It is likely that other countries will also consider plain packaging legislation, depending on the outcome of legal challenges initiated by tobacco companies to the Australian government's initiative.

\section{POLICY ANALYSIS}

\subsection{The Evidence for Plain Packaging}

There are 57 studies about plain cigarette packaging published packaging since 2002. Of these, 27 looked at the impact of health warnings. Their findings demonstrated that large pictorial warnings were more effective in communicating health risks than text-only messages, particularly for populations with low literacy, and inclusion of a quit-line number was associated with significant increases in calls for assistance from smokers. The remaining studies looked at pack design features, such as branding, pack colour, and product descriptors and what effect these had on the cigarettes' appeal to smokers. Their findings indicated that the use of descriptors such as "light", "smooth", "slim", "gold", etc., were frequently associated with a perception of reduced harm. Even the pack colour itself was associated with misperceptions about health risk, lighter colours being seen as an indication of lower cigarette strength, enabling tobacco companies to effectively bypass FCTC's Article 11 about banning misleading or deceptive descriptors [4$6]$.

Tobacco companies' own market testing studies reveal how identical cigarettes presented in packs with different colours and designs could lead consumers to "experience and evaluate them differently when they were smoked" [7]. Branding and other design features were also important elements in the overall appeal of the product, especially for young people. Scheffels found that choice of brand and the design of the package were seen by young people as making important statements about a person's image and status in society, in a similar way to a person's style of dress [8].

These studies support the introduction of plain packaging as a tobacco control measure, for reasons well summarised by Hammond: "increasing the effectiveness of health warnings, reducing false health beliefs about cigarettes, and reducing brand appeal especially among youth and young adults" [6]. Tobacco companies' strong opposition to plain packaging is an indicator of the importance they place on it as a form of advertising [9], particularly in countries like Australia where all other forms of advertising are banned.

Notwithstanding the evidence for the role played by packaging in appealing to, and misleading, smokers and potential smokers, all the plain packaging studies to date have utilised experimentally altered packs [9], which subjects have been able to compare with more familiar and presumably more attractive branded packs. A recent Scottish study provides suggestive evidence of the likely impact of plain packaging. Moodie and colleagues employed a naturalistic approach, asking the smokers in their study to transfer their own cigarettes from the branded pack into a plain brown pack for 2 weeks, but to otherwise smoke as they normally would. Their results showed that simply smoking their usual brand from a plain pack significantly affected smokers' sensory perceptions about the product, as well as heightening their awareness of the health warnings. Some smokers reported forgoing a cigarette rather than bringing the pack out in public [10].

After plain packaging legislation is implemented in Australia in December 2012 and any novelty effect wears off, the true impact of this measure will be apparent. The most important and hoped for outcome will be eliminating the image connotations that branded packageing has for young people, thus removing one avenue for recruiting new initiates to tobacco smoking. The UK government's 2009 review of young people and smoking in England, commissioned to inform its tobacco control strategy, also concluded that "the tobacco industry is exploiting the pack as a medium for advertising the product" and deemed generic packaging an essential step in a youth oriented approach to tobacco control [11].

\subsection{The Australian Tobacco Control Reforms}

As well as plain cigarette packaging, Australia has been introducing other evidence-based tobacco control measures since 2010 as part of its primary health care strategy [12], including increasing tobacco excise by $25 \%$, a mass media campaign focusing on high-risk and hard-to-reach groups, and a national summit on smoking in prisons. These complement its existing framework of policies on smoke-free environments, advertising bans, graphic health warnings on cigarette packs, availability of subsidised smoking cessation aids and Quitline support services.

But will these be enough to reduce daily smoking from $15.1 \%$ in 2010 [13] to the government's target of $10 \%$ or less by 2020? Frohlich points out it is possible that the "low hanging fruit have been picked" after decades of 
tobacco control measures in Canada, and the same may well be true in Australia. She argues for a new focus on the particular needs of the remaining population groups with high rates of smoking [14].

Along with targeting particular populations in the media campaign, the Australian government has allocated additional funding for identified groups, including:

- Indigenous Australians, The high prevalence of smoking (50\%) by indigenous Australians [15] and its contribution to their substantially lower life expectancy led to a clear focus on tobacco reduction strategies in the Australian government's "Closing the Gap” program which began in 2008. The appointment of a National Coordinator for Tackling Indigenous Smoking in 2010 has overseen training of indigenous health workers and tobacco action workers to run community-based prevention and cessation support activities. Other strategies have included an indigenous social marketing campaign and regional community projects, some of which have already proven successful. This approach is supported by a recent international review of smoking cessation interventions in indigenous populations which found that successful approaches were integrated, flexible, and community-based [16].

- People with mental illness. In surveys conducted in Australia and the US, adults with a mental illness were found to be twice as likely to smoke as those without a mental disorder [17]. The authors noted that "As the majority of smokers with mental illness are not in contact with mental health services for their condition, strategies to address mental illness should be included as part of population health-based mental health and tobacco control efforts". While the Australian government has identified people with mental illness as one of the highly disadvantaged groups to target in its current social marketing campaign, its main approach-apart from funding a number of applied research projects on smoking and mental illness-appears to be encouraging State-run health services and health professional bodies to tackle the problem.

- Prisoners. To begin tackling the unacceptably high rate of smoking in Australian prisons, estimated to be 85\% [18], the government organised a national summit in August 2010. The ensuing report highlighted the complexity of tackling an activity which is "the cultural norm in prison", used as an antidote to the pervasive boredom of incarceration, a form of currency, and a management tool, in a setting which is both workplace and home. The report recommended the creation of smoke-free areas with the aim of eventually having all indoor prison areas smoke-free, and greater smoking cessation support including free nicotine replacement therapy for prisoners [18]. The needs of particular groups in prison: people with a mental illness, Indigenous people, substance users and young people, must be factored into any interventions and a coordinated national approach is required.

\subsection{A More Systematic Approach in Primary Health Care}

In addition to fiscal, regulatory, social marketing and other targeted population approaches, the Australian government acknowledged the key role of primary health care in health promotion activities and agreed to strengthen the sector's capacity to tackle lifestyle risk factors more systematically through establishment of a network of primary health care organisations (Medicare Locals) in 2011-2012, and expansion of the role of nurses in general practice [12]. Medicare Locals are charged with developing regional models of care and supporting the primary health care workforce to deliver integrated services responsive to local need. The Practice Nurse Incentives Program encourages practices to employ practice nurses, Aboriginal health workers and allied health workers. Both of these initiatives offer general practice a chance to seize "golden opportunities to intervene with smoking patients” [19].

Despite clear evidence for the effectiveness of brief smoking cessation advice from physicians, with or without nicotine replacement therapy (NRT) or non-nicotine pharmacotherapies such as Bupropion and Varenicline [20], a disappointingly low percentage of smokers receive this support from their doctor [21]. Zwar noted the barriers GPs identified to tackling smoking cessation, but concluded general practice was ideally placed for intervention activities [19], with both GPs and practice nurses being seen as credible and trusted sources of health advice in a familiar setting. Even a modest success rate could have a significant impact on the prevalence of smoking, given that most Australians have at least one general practice visit each year.

The Australian government's tobacco reforms, together with its measures to strengthen primary health care, make this an ideal time for general practice to tackle smoking cessation more systematically. The Australian Primary Care Collaboratives [22], introduced in 2004 to assist primary care to make sustainable improvements in the quality of care it provides to patients, offers a workable model for practices to focus on a particular health issue, identify incremental steps they can take to address it and collect data to measure the outcomes. This model has demonstrated significant improvements in the management of diabetes and coronary heart disease [22] and could similarly be used for more systematic management of smoking cessation. Practices are now well equipped 
with the clinical software to identify the smokers on their patient data-bases and to set electronic prompts for the physician or nurse to review smoking status at the patient's next appointment. Evidence-based cessation guidelines are widely available.

Some of the smokers identified will undoubtedly belong to the "treatment-resistant" group described in the literature [23]. There may be genetic, physiological and psychological factors contributing to an individual's nicotine dependence, so health care practitioners need to work with each smoker to find the most suitable treatment. Smokers feel stigmatised and dislike being "lectured about smoking”, but as “... a failure to talk about smoking was sometimes taken as evidence of tacit support for smoking... it does seem that GPs cannot afford to leave the topic alone" [24]. Smokers in their study stressed "the importance of receiving positive responses from their doctors when they had stopped smoking”.

For some smokers, advice and treatment may only result in temporary cessation, or reduction rather than elimination of their cigarette intake, but this is still beneficial to their health and may provide an eventual "gateway to quitting” [23]. General practitioners and practice nurses are in an ideal position to systematically identify all the smokers in their care and offer all support to quit, adopting a harm-minimisation approach for those who are unwilling or unable to do so completely.

\section{CONCLUSION}

Whether the combined impact of the Australian government's recent tobacco control reforms and its previous measures will be sufficient to reduce daily smoking prevalence to $10 \%$ or less by 2020 , only time will tell. What is more certain is that such reforms offer primary health care a powerful new policy framework to reinforce more systematic approaches to smoking cessation. The Australian government's tobacco reforms, together with its measures to strengthen primary health care, make this an ideal time for general practice to tackle smoking cessation more systematically. The Australian experience of plain packaging offers international colleagues in general practice key lessons about what is needed at the systemic policy level to make a bigger difference to smoking cessation. The achievement of Australia's political leaders in plain cigarette packaging is an extraordinary testament to political will but there is no room for complacency. Primary healthcare sectors must continue to lobby political leaders around the world to tackle smoking at the system level where the motivations and beliefs about smoking are being shaped, especially among disadvantaged groups with lower health literacy.

\section{ACKNOWLEDGEMENTS}

This paper was funded by the Primary Healthcare Research and De- velopment Program, funded by the Australian government's Department of Health and Ageing.

\section{REFERENCES}

[1] Physicians for a Smoke-Free Canada (2011) Plain packaging: Timeline of events.

http://www.smoke-free.ca/plain-packaging/history.htm

[2] Goldberg, M., Kindra, G., Lefebvre, J., Tribu, L., Liefield, J., et al. (1995) When packages can't speak: Possible impacts of plain and generic packaging of tobacco products. Health Canada, Ottawa.

[3] Department of Health \& Ageing (2011) Public consultation on plain packaging of tobacco products. Australian Government, Canberra.

http://yourhealth.gov.au/internet/yourhealth/publishing.ns f/Content/plainpack-tobacco.

[4] Cancer Council Victoria (2011) Plain packaging of tobacco products: A review of the evidence. The Cancer Council, Melbourne.

http://www.cancer.org.au/Healthprofessionals/PositionSta tements/smokingtobaccocontrol/Plainpackagingoftobacco products.htm

[5] Centers for Disease Control and Prevention (2011) Cigarette package health warnings and interest in quitting smoking-14 countries, 2008-2010. Morbidity and Mortality Weekly Report, US Department of Health and Human Services, Atlanta.

[6] Hammond, D. (2010) "Plain packaging” regulations for tobacco control products: The impact of standardising the color and design of cigarette packs. Salud Pública de México, 53, S226-S232.

doi:10.1590/S0036-36342010000800018

[7] Wakefield, M. (2011) Editorial welcome to cardboard country: How plain packaging could change the subjective experience of smoking. Tobacco Control, 20, 321322. doi:10.1136/tc.2011.044446

[8] Scheffels, J. (2008) A difference that makes a difference: Young adult smokers' accounts of cigarette brands and package design. Tobacco Control, 17, 118-122. doi:10.1136/tc.2007.021592

[9] Freeman, B., Chapman, S. and Rimmer, M. (2008) The case for plain packaging of tobacco products. Addiction, 103, 580-590. doi:10.1111/j.1360-0443.2008.02145.X

[10] Moodie, C., Mackintosh, A., Hastings, G. and Ford, A. (2011) Young adult smokers' perceptions of plain packaging: A pilot naturalistic study. Tobacco Control, 20, 367-373. doi:10.1136/tc.2011.042911

[11] Amos, A., Angus, K., Bostock, Y., Fidler, J. and Hastings, G. (2009) A review of young people and smoking in England. Public Health Research Consortium, Edinburgh.

[12] Commonwealth of Australia (2010) Building a 21st century primary health care system: Australia's first national primary health care strategy. Canberra.

[13] AIHW (2011) 2010 National drug strategy household survey report. Australian Institute of Health and Welfare, Canberra. 
[14] Frohlich, K. (2008) Is tobacco use a disease? Canadian Medical Association Journal, 179, 880-882. doi:10.1503/cmaj.080545

[15] Pink, B. and Allbon, P. (2008) Health and welfare of Australia's aboriginal and Torres Strait Islander peoples. Australian Institute for Health and Welfare, Canberra.

[16] DiGiacomo, M., Davidson, P., Abbott, P., Davison, J., Moore, L., et al. (2011) International smoking cessation in indigenous populations of Australia, New Zealand, Canada and the United States: Elements of effective interventions. International Journal of Environmental Research and Public Health, 8, 388-410.

[17] Lawrence, D., Mitrou, F. and Zubrick, S. (2009) Smoking and mental illness: Results from population surveys in Australia and the United States, BMC Public Health, 9, 285.

[18] Butler, T. and Stevens, C. (2011) National Summit on tobacco smoking in prisons: Report on the summit. National Drug Research Institute, Perth.

[19] Zwark, N. and Richmond, R. (2006) Role of the general practitioner in smoking cessation. Drug and Alcohol Review, 25, 21-26. doi:10.1080/09595230500459487

[20] Society for Research on Nicotine and Tobacco (2011) Efficacy: Key findings. http://treatobacco.info/en/page_170.php

[21] Zwar, N., Richmond, R., Halcomb, E., Furler, J., Smith, J., et al. (2010) Quit in general practice: A cluster randomised trial of enhanced in-practice support for smoking cessation. BMC Family Practice, 11, 59.

[22] The Australian Primary Care Collaboratives (2011). http://www.apcc.org.au/images/uploads/APCC_Program Poster110412.pdf

[23] Bittoun, R. (2007) The “treatment-resistant” smoker. Medicine Today, $\mathbf{8}, 16-24$.

[24] Hansen, E. and Nelson, M. (2011) How cardiac patients describe the role of their doctors in smoking cessation: A qualitative study. Australian Journal of Primary Health, 17, 268-273. doi:10.1071/PY10082 